BLS 35, No 1 2009. DOI: http://dx.doi.org/10.3765/bls.v35i1.3599

(published by the Berkeley Linguistics Society and the Linguistic Society of America)

\title{
Span of High Tones in Hong Kong English*
}

\author{
WINNIE H.Y. CHEUNG \\ Hong Kong Baptist University
}

\section{Introduction}

The English spoken by Hong Kongers (typically called Hong Kong English, henceforth HKE) has a distinct tonal quality (Luke 2000, Wee 2008). ${ }^{1}$ The key data are shown in (1)-(3), where syllables with high tones are marked with acutes "á", low tones with graves "à" and falling tones with caps "â". 2 Mid tone syllables are left unmarked, and bold typeface indicates stressed syllables.

(1) Words with a sequence of high tones
a. ínfórmátiòn
b. édúcátiòn
c. bénéfíciàl
d. idéntífícátiòn

(2) Words without a sequence of high tones
a. locátìon
b. partícipàte
c. irrégulàr
d. Cánadà

(3) Words with falling tones
a. bâll
b. pînch

Stress can be located by standard diagnostics which for length considerations shall not be discussed here. The above data allows the following characterization of HKE.

\footnotetext{
* This research is supported by FRG/07-08/II-09. The author is grateful to her informants and to John McCarthy, Chilin Shih, Larry Hyman, Lian-Hee Wee and the audience of the PUFF Group, Workshop on Cantonese 7, Second Theoretical Phonology Conference (TPC) and BLS 35 for valuable feedback. Remaining errors are mine.

${ }^{1}$ Regardless of HKE's language status, the fact that it has an identifiable accent would warrant serious phonological study (Hung 2000).

${ }^{2}$ Words were uttered in isolation; only content words are considered in this research. Recordings were sampled at $22050 \mathrm{~Hz}$ from one primary informant and two secondary ones for convergence.
} 


\section{Span of High Tones in Hong Kong English}

\section{Characterization of HKE}

a. A stretch of high tones spans the first stress-bearing syllable and the last stress-bearing syllable inclusive;

b. Multi-syllabic words with only one stress have only one high tone;

c. Monosyllabic words have falling tones; and

d. Final syllables always contain a low tonal element. ${ }^{3}$

Evidently the span of high tones is a derivative of stress (not vice versa). Stress placement in HKE is, however, beyond the present scope; I shall assume it is calculable from generalizations in Hung (2005).

This paper aims to account for the tonal patterns in HKE, and makes the arguments listed below:

i. The sequence of high tones is best represented as the multiple association of a single high tone autosegment with all syllables within the domain defined by the first stressed and last stressed syllables;

ii. Falling contour in monosyllabic words is the result of associating a high tone $(\mathrm{H})$ and a boundary low tone $(\mathrm{L} \%)$ with that syllable;

iii. Remaining syllables are toneless phonologically, but surface as mid tones as a phonetic default.

The next section presents an acoustic analysis of the tonal contrasts in HKE. Subsequent sections provide phonological analysis before ending with a conclusion.

\section{Phonetic Bases}

Although tones are common in Chinese languages, their presence in English would be somewhat unexpected. However, since HKE arose out of the contact between Cantonese and English, transference is likely. In any case, the presence of tonal contrasts can be easily verified through acoustic analyses, as presented in (5). ${ }^{4}$

The pitch tracks clearly show the tonal distinctions, matching those tonal transcriptions given in (1)-(3).

For the most part, the tones consist of level high or mid tones, as in (5a) and (5b). There are however two things that deserve special mention. Firstly, final syllables appear to be somewhat inconsistent in whether they are low level tones like (5c) or low falling ones like (5a). Secondly, the penultimate syllable has a falling pitch contour (indicated by the circle, $(5 \mathrm{c})$ ).

\footnotetext{
3 The characterization here is in fact only for one variety of HKE, which like other new Englishes, exhibits variation across speakers. Another variety will be discussed later in section 4 .

${ }^{4}$ All spectrograms and pitch tracks in this paper are generated using Praat (ver. 5.0.06, Boersma and Weenink 2008).
} 


\section{Winnie H. Y. Cheung}

(5) Spectrograms showing pitch tracks

a. locátion

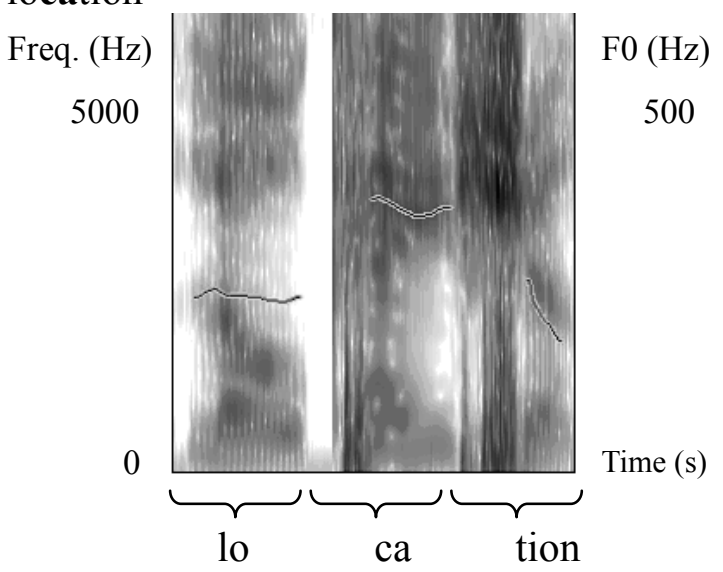

b. idéntífícátiòn

Freq. (Hz)

5000

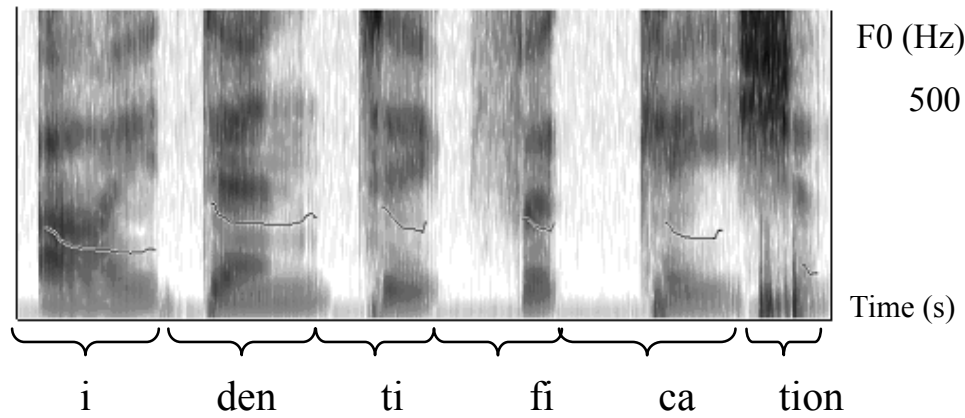

c. partícipàte

Freq. $(\mathrm{Hz})$

5000

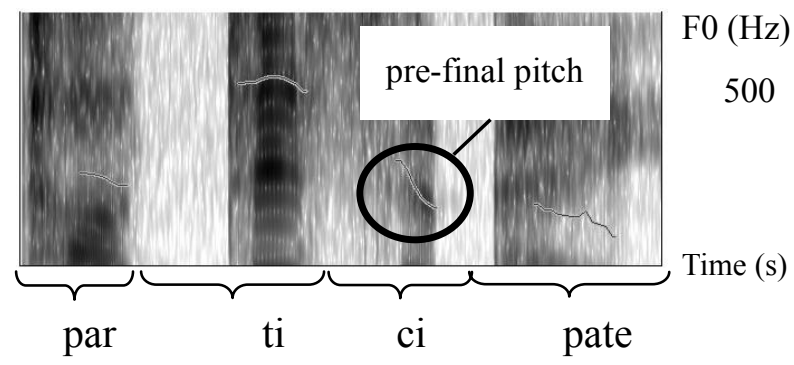

d. pinch

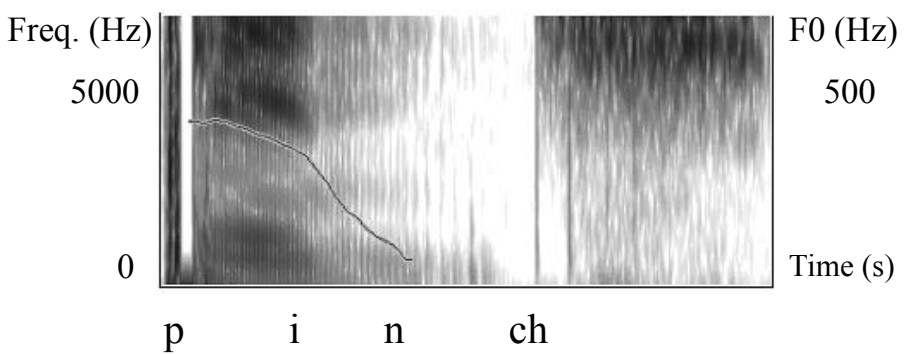


Common to all the cases shown in (1) - (3) is a low tonal element at the rightmost edge. Evidently, this is a boundary tone, and indeed there is evidence for that interpretation. For instance, consider a HKE utterance of the sentence The irregular situation looks threatening. The attested tonal pattern is: The irrégúlár sítúátion lóoks thréatenìng, (6).

\section{(6) Pitch tracks of The irrégúlár sitúátion lóoks thréatening}

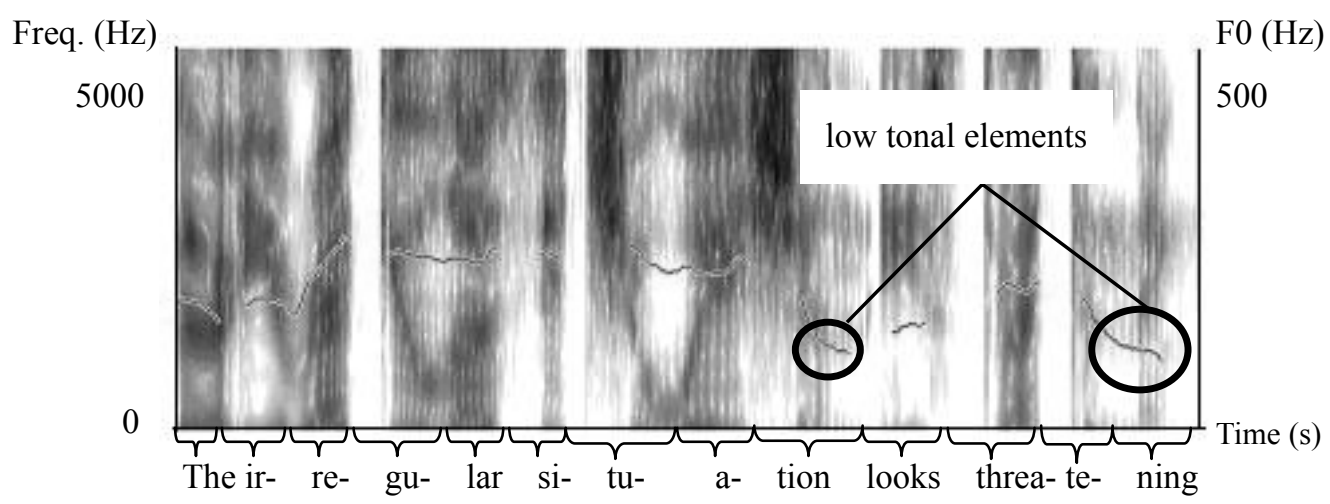

As shown in (6), low tones are only realized at the final syllables of situation and threatening suggesting that it is a boundary tone of a certain domain, in this case, a Phonological Phrase (PhP, Inkelas and Zec 1990, Nespor and Vogel 1986, and Selkirk 1984, 1986). I will use $\mathrm{L} \%$ as a symbol to indicate this low $\mathrm{PhP}$ boundary tone. The fact that the final syllable of irregular in (6) does not have a low tone supports the argument for the L\%.

With $\mathrm{L} \%$ at the end of a PhP, the falling pitch of monosyllabic words like pinch in (5d) would be explained as a H-L\% sequence. It also follows that the falling contour of the pre-final syllable in $(5 \mathrm{c})$ is a transitional fall from $\mathrm{H}$ towards the phrase final $\mathrm{L} \%$, similar to the falling tone of monosyllabic words. ${ }^{5}$ This suggests that pre-final unstressed syllables are phonologically toneless, the pitch being solely determined by an interpolation from $\mathrm{H}$ to the target $\mathrm{L} \%$. Consequently, one could explain why the final pitch in (5a) is low falling and in (5c) low leveled. In (5a) $\mathrm{H}$ immediately precedes $\mathrm{L} \%$, but in (5c) $\mathrm{H}$ and $\mathrm{L} \%$ are separated by an unstressed (hence toneless) syllable.

Implicit in the account of the effects of $\mathrm{L} \%$ above is the notion that phonologically toneless syllables are articulated in any pitch that occurs in the transition of one toned syllable to another, in this case as $\mathrm{H}$ makes a transition to $\mathrm{L} \%$. If the assignment of $\mathrm{H}$ tone is determined by stress (specifically by the domain defined by the edgemost stresses), then by the same logic, syllables that precede the initial stressed syllable would also be phonologically toneless. However, initial syllables

\footnotetext{
${ }^{5}$ Contrary to Luke (2000) who described non-high penultimate syllables as L, a description inconsistent with the evidence obtained here.
} 


\section{Winnie H. Y. Cheung}

would surface with mid-range pitch as a phonetic default with minimal articulatory effort.

With the phonetic correlates of tone in place, the next section moves on to an autosegmental study.

\section{Autosegmental Analysis of Tones in HKE}

The span of $\mathrm{H}$ tones that coincides with the domain defined by the edgemost stresses appears to be exactly the kind of phenomenon expected in an autosegmental conception of tone. In fact, the tonal generalizations identified in the previous section for HKE can be captured in autosegmental terms (Leben 1973, 1978 and Goldsmith 1976), as depicted in (7).

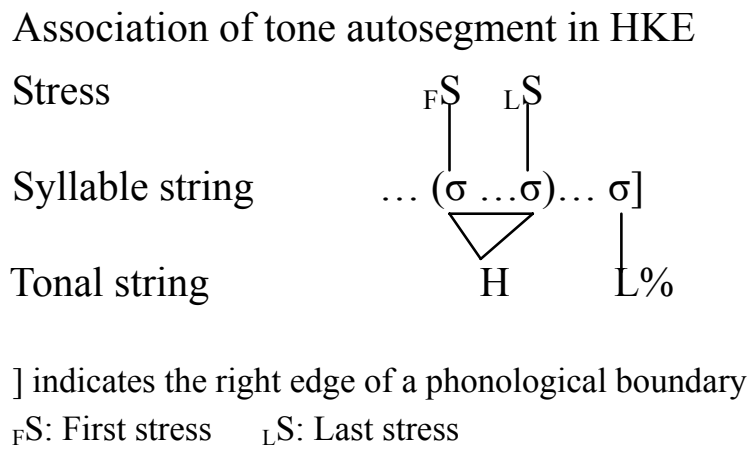

The span of high tone syllables is likely to be the result of having only one $\mathrm{H}$ autosegment associated with all syllables between the edgemost stress-bearing syllables, inclusive. For convenience, I shall refer to the domain defined by the edgemost stress-bearing syllables as the stress domain, indicated with a pair of parentheses $(\sigma \ldots \sigma)$. This association of a single $H$ to all syllables in the stress domain would be the simplest analysis in terms of explaining why the span is not broken (more discussion on NOGAP in section 3.1) and with maximal adherence to the Obligatory Contour Principle (OCP, Leben 1973, more in section 3.1). ${ }^{6}$

When there is only one stressed syllable in the PhP (as in cases like (2a)), the stress domain would consist of only one syllable. Beyond the stress domain, any remaining syllables that are neither associated with $\mathrm{H}$ nor $\mathrm{L} \%$ (dots outside the stress domain) are toneless and surface with whatever pitch the phonetics demands, falling if transitional between $\mathrm{H}$ and $\mathrm{L} \%$ or $\mathrm{M}$ otherwise. The phenomenon of toneless syllables surfacing as mid tones follows from the markedness constraints of tones in standard Optimality Theoretic accounts, inherited from the general theory of feature underspecification and defaults (Pulleyblank 1992, Steriade 1995, and Myers 1998), in turn grounded in physiological ease.

\footnotetext{
${ }^{6}$ For convenience, a tone is associated with a syllable in this paper. Properly speaking, the tone-bearing unit (TBU) for HKE is probably the mora. Consider cat which only has a $\mathrm{H}$ tone and pinch which has a $\mathrm{HL} \%$ sequence.
} 
It should be noted that for the purpose of illustration, I have specified $\mathrm{H}$ and $\mathrm{L} \%$ on the tonal tier. However, since these two tones are predictable and derivable, they do not need to be stipulated underlyingly and in fact should not be, since as mentioned earlier, tones are derivates of stress in HKE, and stress is by and large calculable.

With the idea of autosegments in place, (8) illustrates the span of $\mathrm{H}$ tones in actual $\mathrm{HKE}$ cases, $\mathrm{F}$ S and ${ }_{\mathrm{L}} \mathrm{S}$ indicating first stress and last stress within the $\mathrm{PhP}$ respectively.

Association of tone autosegment in identification (cf.(1d))

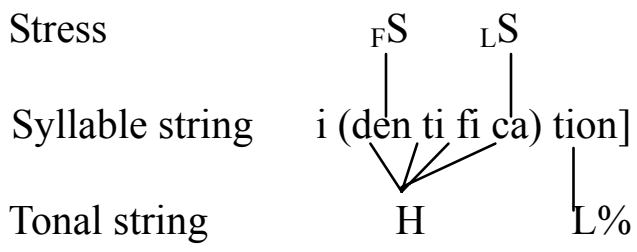

The schema in (8) also correctly predicts the tonal patterns of HKE beyond the word level such as the sentence in (6), repeated below with an illustration on tonal associations in (9). ${ }^{7}$

(9) Association of tone autosegment in sentence (6)

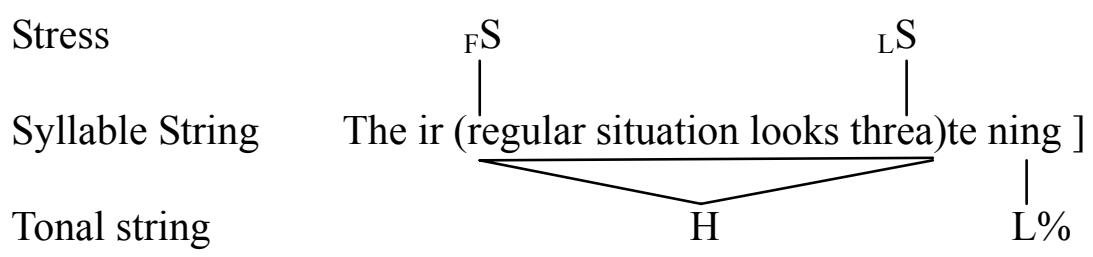

\section{An OT Analysis}

Given the autosegmental account of the tonal distributions in HKE in section 2, the next step would be to account for why the tones of HKE pattern the way they do. For instance, why is it that a stressed syllable is associated with $\mathrm{H}$ but not L? In Optimality Theory (OT, Prince and Smolensky 1993/2004), these questions could be answered by the interactions of a set of universal constraints that come into play.

\subsection{An OT Account for Multiple High Tone Association in HKE}

Recall that $\mathrm{H}$ is always associated with a stressed syllable in HKE. In fact, this is found to be unmarked in many tonal languages (such as Lithuanian and Mixtec) and it could be stated in terms of the following markedness constraints established in de Lacy $(1999,2002)$.

${ }^{7}$ There are exceptional cases. For instance, instead of *irrégúlár lócátìon, we only got irrégúlár locátion. The tone of the initial syllable "lo-" in location is expected to be $\mathrm{H}$ given that the syllable is within a stress domain, but it turns out to be $\mathrm{M}$. At this stage, it remains uncertain if cases like 'location' are lexical exceptions, thus will have to be left for future exploration and investigation. 


\section{Winnie H. Y. Cheung}

(10)

$\mathrm{HD} / \mathrm{H}$

A prosodic head prefers a high tone.

NON-HD/H

A non-prosodic head does not prefer high tones.

Following standard assumptions, the HKE prosodic head is a stressed syllable (indicated with $\boldsymbol{\sigma}$ throughout) and a non-head an unstressed syllable. Thus candidates that have $\mathrm{H}$ associated with the stressed syllables would satisfy this constraint. Together with $\mathrm{NON}-\mathrm{HD} / \mathrm{H}$, this would ensure that unstressed syllables which are outside the stress domain would not have high tones. However, these two constraints themselves are insufficient to make the case for the high tone spreading in $\mathrm{HKE}$. $\mathrm{HD} / \mathrm{H}$ is neutral to whether $\mathrm{H}$ is multiply linked to a number of stressed syllables or whether there are many Hs to be linked to the syllables. In effect, $\mathrm{HD} / \mathrm{H}$ does not trigger spreading and it does not prevent more Hs from being present either. However, there are other established constraints that would step in to yield the effect of spreading one $\mathrm{H}$ to all the syllables in the stress domain. These constraints are listed in (11).

(11) Constraints triggering multiple high tone association

NOGAP (Kiparsky 1981, Yip 2002:84)

Mutliply linked tones cannot skip syllables. ${ }^{8}$

OCP-H

Two adjacent identical tones are prohibited in the tonal tier.

To see how (11) works, and to find the ranking required of these constraints, consider a set of possible candidates for an input in (12).

Input: $\boldsymbol{\sigma} \sigma \sigma \sigma]$ (cf. (1a) information $)^{9}$

Relevant Candidates

a.

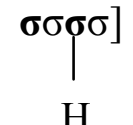

d.<smiles>O=CO</smiles>

b.

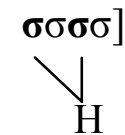

e.<smiles>O=C1CO1</smiles>

Notice that the input in (12) does not assume any underlying H. This is crucial because, as mentioned in the introduction, tones are computed out of stress in

${ }^{8}$ Cf. footnote 6.

${ }^{9}$ For convenience, the inputs here are assumed to be a parsed string of syllables with stresses and a PhP boundary indicated. However, syllable structure, stress and PhP boundary are derivable from other constraints, omitted here in the interest of focus. 
HKE, and stress placement alternates with suffixation, thus $\mathrm{H}$ cannot be stipulated in the input. Also, $\mathrm{HD} / \mathrm{H}$ would ensure $\mathrm{H}$ epenthesis anyway, making stipulation redundant. ${ }^{10}$ The effect of multiple high tone association could be achieved by ranking $\mathrm{HD} / \mathrm{H}$, NOGAP and OCP-H all above NON-HD/H, as illustrated in Tableau (13).

(13) Evaluation of high tone spreading

\begin{tabular}{|c|lllll|l|}
\hline $\boldsymbol{\sigma} \sigma \boldsymbol{\sigma} \sigma]$ & $\mathrm{HD} / \mathrm{H}$ & NOGAP & OCP-H & NON-HD/H \\
\hline$(12 \mathrm{a})$ & $* !$ & & & & \\
\hline$(12 \mathrm{~b})$ & & $* !$ & & $*$ \\
\hline$(12 \mathrm{c})$ & & & $* ! *$ & \\
\hline$(12 \mathrm{~d})$ & & & $* !$ & \\
\hline$\circledast(12 \mathrm{e})$ & & & & $*$ \\
\hline
\end{tabular}

In (13), candidate (12a) is ruled out by the fatal violation of $\mathrm{HD} / \mathrm{H}$ since the first stressed syllable is not associated with a $\mathrm{H}$ tone. Candidate (12b) fatally violates NOGAP because the associations skip the second syllable. This leaves us candidates (12c-e). Both candidates (12c) and (12d) are eliminated for their violations of OCP-H. Candidate (12e) turns out to be the optimal output despite its trespass on NON-HD/H.

\subsection{Default Tones and $L \%$}

The fact that default tones surface on toneless syllables which are outside the stress domain can be easily captured by the universal markedness constraints on tones, and likewise for the boundary $\mathrm{L} \%$ :

${ }^{*} \mathrm{H}$

No high tones

$* \mathrm{~L}$

No low tones

ANCHOR L\%-RT

The right edge of $\mathrm{PhP}$ must have a $\mathrm{L} \%$.

With $* \mathrm{H}$ and ${ }^{*} \mathrm{~L}$, mid-tones (M) are really just phonetic implementation of phonologically toneless syllables. ANCHOR L\%-RT would ensure L\% at the right edge of a $\mathrm{PhP}$ in $\mathrm{HKE}$.

Although there are no ranking arguments with respect to ANCHOR L\%-RT, ${ }^{*} \mathrm{H}$, or any of the constraints in (10) and (11), ANCHOR L\%-RT must be ranked higher than ${ }^{*} \mathrm{~L}$ as shown in (15).

\footnotetext{
${ }^{10}$ Though no input $\mathrm{H}$ is assumed here, the account presented here would nonetheless predict the correct output for potential inputs that have stipulated $\mathrm{H}$, as required by Richness of the Base. Thanks to John McCarthy for pointing this out to me.
} 


\section{Winnie H. Y. Cheung}

(15)

Ranking argument for ANCHOR L\%-RT and * $\mathrm{L}$

\begin{tabular}{|l||c|c|}
\hline $\boldsymbol{\sigma}]$ (cf. (3a)) & ANCHOR L\%-RT & $*$ L \\
\hline \hline \multirow{2}{*}{ a. $\boldsymbol{\sigma}]$} & & $*$ \\
\hline b. $\boldsymbol{~}$ ] $\%$ & & \\
$\mathrm{H}$ & $* !$ & \\
\hline
\end{tabular}

As an interim summary, (16) below provides the constraint ranking hierarchy.

(16) Constraint Ranking Hierarchy

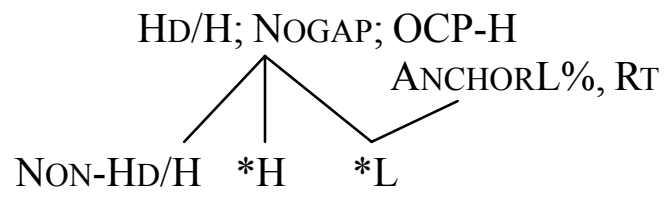

\section{Factorial Typological Predictions}

Like most contact languages, HKE, which is a hybrid of Cantonese and English, is not homogenous across speakers. Other than the variety presented in the preceding sections, there is another variety which I shall call $\mathrm{HKE}^{\prime}$. How $\mathrm{HKE}^{\prime}$ compares with HKE can be seen from the data in (17).

Key data from $\mathrm{HKE}^{\prime}$
a. bâll
b. pînch
cf. (3)
c. locátion
d. partícipàte
cf. $(2 a-b)$
e. informátiòn
f. identificátiòn
cf. (1a), (1d)

Key: Bold $=$ stress

From (17), it is evident that HKE' and HKE share a number of characteristics. Both varieties have (i) falling tones for monosyllables, (ii) high tones for stressed syllables and (iii) L\% in the rightmost edge of the word/utterance. However, unlike $\mathrm{HKE}, \mathrm{HKE}^{\prime}$ has only one $\mathrm{H}$ on the surface, corresponding to the syllable that carries the main stress.

The difference between HKE and HKE' can be captured with the same set of constraints using a different ranking, such as that in (18).

(18) Constraint ranking hierarchy for tonal patterns in $\mathrm{HKE}^{\prime}$ NON-HD/H ; NOGAP ; OCP-H » HD/H

The ranking hierarchy in (18) shows only those constraints relevant to the distribution of high tones. This illustrates that $\mathrm{HKE}^{\prime}$ is actually predicted by the 


\section{Span of High Tones in Hong Kong English}

factorial typology of the constraints used in the account for HKE. The applicability of the same set of constraints across both varieties argues for the essential validity of the analysis presented in the preceding sections of this paper.

\section{Conclusion}

This paper explains that the patterns of tones in HKE arise out of a single $\mathrm{H}$ multiply-linked to all the syllables in the stress domain of the PhP. Any residual syllables outside the stress domain are phonologically toneless and surface by phonetic defaults.

The HKE PhP has a L\% at the right boundary, which is responsible for the presence of falling tones in monosyllabic words and transitional mid tones between the final syllable of a stress domain and the final syllable of a multi-syllabic word. The presence of tones in HKE as discussed here is not committed to establishing if HKE is a tonal language or tone accent language like Japanese, though it is hoped that this study would open up these doors for research.

\section{References}

Boersma, Paul and David Weenink. 2008. Praat: Doing phonetics by computer (Version 5.0.06) [Computer program]. Retrieved Feb 28, 2008, from http://www.praat.org/

De Lacy, Paul. 1999. Tone and prominence. Rutgers Optimality Archive \#333-0799. http://roa.rutgers.edu/

De Lacy, Paul. 2002. The interaction of tone and stress in Optimality Theory. Phonology 19:1-32.

Goldsmith, John. 1976. Autosegmental phonology. Ph.D. diss., Massachusetts Institute of Technology. Published 1979, New York: Garland Press.

Hung, Tony T.N. 2000. Towards a phonology of Hong Kong English. World Englishes 19(3):337-56.

Hung, Tony T.N. 2005. Word stress in Hong Kong English: A preliminary study. HKBU Papers in Applied Language Studies 9:29-40.

Inkelas, Sharon, and Draga Zec, eds. 1990. The phonology-syntax connection. Chicago: University of Chicago Press.

Kiparsky, Paul. 1981. Vowel harmony. Ms., Massachusetts Institute of Technology.

Leben, William. 1973. Suprasegmental phonology. Ph.D. diss., Massachusetts Institute of Technology.

Leben, William. 1978. The representation of tone. In Victoria A. Fromkin, ed., Tone: A linguistic survey, 177-219. New York: Academic Press.

Luke, K.K. 2000. Phonological re-interpretation: The assignment of Cantonese tones to English words. Paper presented at the $9^{\text {th }}$ International Conference of Chinese Linguistics (ICCL-9), June 26-28, 2000, National University of Singapore. 


\section{Winnie H. Y. Cheung}

Myers, Scott. 1998. Surface underspecification of tone in Chichewa. Phonology 15:367-391.

Nespor, Marina, and Irene Vogel. 1986. Prosodic phonology. Dordrecht: Foris .

Prince, Alan, and Paul Smolensky. 1993/2004. Optimality Theory: Constraint interaction in generative grammar. Malden, MA: Blackwell.

Pulleyblank, Douglas. 1995. Feature geometry and underspecification. In J. Durand and F. Katamba, eds., New frontiers in phonology: Atoms, structures, derivations, 3-33. New York: Longman.

Selkirk, Elisabeth O. 1984. Phonology and syntax: The relation between sound and structure. Cambridge, MA: MIT Press.

Selkirk, Elisabeth. 1986. On derived domains in sentence phonology. Phonology Yearbook 3:371-405.

Steriade, Donca. 1995. Underspecification and markedness. In John A. Goldsmith, ed., The handbook of phonological theory, 114-174. Cambridge, MA: Blackwell.

Wee, Lian Hee 2008. Phonological patterns in the Englishes of Singapore and Hong Kong. World Englishes 27(3/4): 480-501.

Yip, Moira. 2004. Tone. Cambridge: Cambridge University Press.

Winnie H.Y. Cheung

Hong Kong Baptist University

Department of English Language and Literature

Kowloon Tong, Hong Kong SAR

0000 China

winniehtc@gmail.com 